\title{
Bitácora, serendipia y multimedios: Construyendo metodologías creativas en la investigación artística
}

\section{logbook, serendipity and multimedia: Building creative methodologies in artistic research}

DOI: $10.46814 /$ lajdv3n6-029

Recebimento dos originais: 01/11/2021

Aceitação para publicação: 20/12/2021

\author{
Dra. Yosi Anaya Morales \\ Instituto de Artes Plásticas \\ Universidad Veracruzana \\ E-mail: yanaya@uv.mx / tallerdevientos@hotmail.com \\ Mtro. Xavier Cózar Angulo \\ Instituto de Artes Plásticas \\ Universidad Veracruzana \\ E-mail: xcozar@uv.mx / xcozar@gmail.com
}

\section{RESUMEN}

En las artes no existe una sola metodología para construir una investigación y por consiguiente, tampoco en la realización de obra creativa. La metodología es lo que va construyendo el artista en cada paso, particularmente si sus productos abarcan varias disciplinas. Por otro lado, el investigador artista tiene la misión de no sólo producir su obra, sino la de investigar a fondo la problemática que le mueve, tanto en los medios representativos como en la parte documental en que puede sustentar su discurso plástico y su propuesta estética.

Dado que el campo de las artes es uno de constante fluctuación, los conceptos (teóricos y problemáticas) toman preponderancia, para dotar a la obra con cierta trascendencia, así mismo la investigación en torno a ella. Partiendo del hecho de que sin pregunta no hay investigación, este texto propone tres tácticas para hacer más rica la experiencia creativa y de investigación en las artes. Siendo éstas simultáneas aunque divergentes, a la vez, son complementarias:

1. La bitácora, como medio de experimentar el mundo y reflexionar la impronta.

2. La serendipia implica apertura a lo nuevo o inesperado.

3. Los multimedios implican el poder cruzar disciplinas para mejor llevar a cabo la representación y mensaje.

Basándonos en la postura del dialogismo establecida por Bakhtin, vemos ésta como una ruta en que los diferentes senderos, materiales, técnicas y tácticas pueden tener cabida, permitiendo el diálogo constante y constructivo entre todos estos aspectos, el manejo de múltiples posibilidades y el desarraigo de patrones establecidos. Este proceso implica transgredir las fronteras ortodoxas de la academia y sus disciplinas formales, moviendo al artista-investigador fuera de su zona de confort a propuestas nuevas.

Palabras claves: creatividad, investigación, bitácora, serendipia, multimedios.

\section{ABSTRACTA}

In the arts there is no single methodology to build a research and therefore, neither in the realization of creative work. The methodology is what the artist builds at each step, particularly if his products cover several disciplines. On the other hand, the artist researcher has the mission not only to produce his 
work, but also to investigate in depth the problems that move him, both in the representative means and in the documentary part in which he can sustain his plastic discourse and his aesthetic proposal. Since the field of the arts is one of constant fluctuation, the concepts (theoretical and problematic) take preponderance, to provide the work with certain transcendence, as well as the investigation around it. Starting from the fact that without questions there is no research, this text proposes three tactics to make the creative and research experience in the arts richer. Although they are simultaneous and divergent, they are complementary at the same time:

1. The logbook, as a means of experiencing the world and reflecting on imprinting.

2. Serendipity implies openness to the new or unexpected.

3. Multimedia implies the power to cross disciplines in order to better carry out the representation and message.

Based on the position of dialogism established by Bakhtin, we see this as a route in which different paths, materials, techniques and tactics can be accommodated, allowing for constant and constructive dialogue between all these aspects, the handling of multiple possibilities and the uprooting of established patterns. This process implies transgressing the orthodox boundaries of the academy and its formal disciplines, moving the artist-researcher out of his comfort zone to new proposals.

Keywords: creativity, research, log, serendipity, multimedia.

En las artes no existe una sola metodología para construir una investigación y por consiguiente tampoco en la realización de obra creativa. La metodología es lo que va construyendo el artista en cada paso, particularmente si sus productos abarcan varias disciplinas, es decir toman diversas formas, utilizando disciplinas variadas para comunicar mejor su mensaje. El investigador-artista, por otro lado, tiene la misión de no sólo producir su obra, sino la de investigar a fondo la problemática que propone, tanto en los medios representativos como en la parte documental en que puede sustentar su discurso plástico y su propuesta estética.

Con frecuencia se ha establecido una diferencia cuasi taxonómica en las artes, mientras que por un lado se privilegia la investigación pura, es decir teórica, por el otro se privilegia la investigación práctica (ejecución de obra, generalmente en la línea o modalidad de trabajo del artista), y ello provoca muchas veces el encajonamiento y la separación de las disciplinas.

El campo de las artes está en continuo movimiento, reinvención y transformación. El artista actual no puede estar parado decididamente en el mismo punto, ya que su obra carecería de propuesta y vigencia: Nunca se visita el mismo río porque el río es en cada instante diferente ${ }^{l}$. Asimismo, el campo de las artes es uno de constante fluctuación en que los conceptos, teorías y problemáticas toman preponderancia, para dotar a la obra con cierta trascendencia. De hecho, para que la obra tenga relevancia, un punto de incisión en el pensamiento de alguien o bien de un sector, deberá abarcar cierta problemática y darle un visión particular que intrigue, denuncie, cuestione o abogue.

1 Proviene del dicho de Heráclito siglo V a.C.: "Ningún hombre visita el mismo río dos veces." 
El teórico de arte norteamericano Hal Foster ${ }^{2}$ menciona que el artista debe tener una visión paraláxica o en parallax, que es una visión desde dos posturas distintas sobre el mismo objeto, esto de modo metafórico implica ver a través del visor de la cámara el objetivo que se abordará, sin quitar el otro ojo a todo lo demás. Involucra ver dos cosas a la vez, el objetivo y el entorno donde éste se ubica.

En este sentido la formación de los artistas deberá tomar rutas más amplias que las anteriormente establecidas por las academias; se trata de abrirse a distintas disciplinas y campos del quehacer humano. Basarse en las práctica disciplinar a la vez que se ubica en el contexto de una problemática que está inmersa en el panorama al que está dirigiéndose su contexto. Sea esta la sociedad, un problema particular como la ortodoxia en todas los aspectos de la vida, la economía, la cultura, la religión, la educación, la ética, los modos de pensamientos, la moral, lo absurdo o trivial, lo vano, el caos, el fatalismo, o todo lo contrario.

Partiendo del hecho de que sin pregunta no hay investigación, es necesario establecer procedimientos, justificación y metas-objetivos para conformarla. Así como hay inicio (la investigación) hay un final (en este caso la propuesta plástica), que a la vez abre el camino para un nuevo inicio. Muchas veces ésta se haya respaldada por un contenido textual, teórico, histórico, social, cultural, entre otros. También se proceden con la experimentación, ejercicios de la práctica apoyados en la intuición.

Esta ponencia propone tres tácticas para hacer más rica la experiencia creativa y de investigación en artes, siendo éstas simultáneas aunque divergentes, y a la vez complementarias: La

\section{bitácora, la serendipia y los multimedios.}

1.

La bitácora ese cuaderno de apuntes o bocetos, acompaña al artista prácticamente en cada momento de su quehacer cotidiano. En él vuelca sus inquietudes, observaciones, apuntes, notas de ideas, bocetos, diagramas, gráficas. Se vuelve una extensión de uno mismo, creando un diálogo con la conciencia y subconsciencia del artista. El término viene de francés bitacle (por habitacle), especie de armario, fijo a la cubierta e inmediato al timón, en que se pone la aguja de marear, habiendo un cuaderno de bitácora que documenta los eventos, peripecias y desarrollo del viaje.

La bitácora también es llamada "La mente sin cráneo del artista"33 En este cuaderno de trabajo, a manera de notas, toman forma las ideas (incipientes o desarrolladas), volviéndose un medio para experimentar el mundo y reflexionar la impronta. Mediante la ejecución de acciones tales como

2 Ver: Hal Foster en The Return of the Real: The Avant-Garde at the End of the Century, 1996. MIT Press, en especial el capítulo "The Artist as Etnographer".

3 bitacoradeunartista.com 
escribir, dibujar, anotar instancias cotidianas, inesperadas y hasta posiblemente insignificantes, permite al practicante de las artes establecer una dinámica cognitiva propia que lo conduzca a la construcción de nuevos mundos posibles y lo acerquen al proceso individual de establecer sus propios mecanismos de expresión e interpretación de la realidad,

La importancia de captar sueños, e inquietudes, de canalizar cuestiones de lo metafísico, lo existencial, la estética del arte y la filosofía contemporánea. Volcar inquietudes, mismas que repercutirán en la estilística y estética contemporáneos que proponga el artista y le otorguen un lugar dentro del ámbito artístico.

Para que un bitácora tenga vida deberá ser el camino del proceso de unir esas ideas que brinden la posibilidad de llevar a cabo una experiencia que conduzca a la materialización de un proyecto. Es decir, el diálogo que se establece con ese acompañante creativo, que a la vez es una externalización de uno mismo - permite plasmar visiblemente lo pasajero, que pueda servir en la concretización de la obra. Mientras se mantenga de manera procesual y como medio de reflexión la bitácora está viva.

Sin embargo, la bitácora como documento a posteriori del proceso artístico, es meramente un simulacro, un representámen de lo que sucedió, una ficción, una máquina que articula los elementos dispersos del proceso en un todo orgánico. Es una labor de edición, de reconstrucción, de justificación y análisis. ${ }^{4}$

Así, la bitácora ha acompañado a connotados artistas como Da Vinci, Picasso, Frida Kahlo, Paul Klee, y muchos otros, siendo ésta un laboratorio y espacio preliminar al acto artísitico. Tan notable e intersante se ha vuelto este medio que se han realizado importantes exposiciones de las bitácoras de artistas. De importancia notable son los cuadernos de Paul Klee, que llevaban los apuntes que sirvieron para impartir sus clases en la Bauhaus. Los cuadernos de Leonardo Da Vinci, de altísimo valor en la actualidad, documentan sus preocuapaciones artísticas y búsquedas, y han servido como antecedentes a los modelos recreados en la actualidad de aparatos voladores y diversos mecanismos. El llamado Diario de Frida Kahlo fungió como una práctica creativa paralela a la pintura, en que pudo vertir su intimidad, sueños, anhelos y pinturas (principalmente acuarelas) de manera libre.

El documento final - es decir cuando se llenan las páginas del cuaderno del momento - puede servir en el corto, mediano y largo plazos como un recurso para retomar ideas que no se desarrollaron, dando la pauta a mayor creatividad y a la maduración de ideas.

2.

La serendipia es un descubrimiento o hallazgo afortunado cuando se está buscando una cosa distinta. En términos más generales se puede, denominar así también a la casualidad, coincidencia o

4 Emiliano Ortega Rousset en http://permutaciones.wordpress.com/ 
accidente. Estas casualidades o coincidencias pueden ser la pauta para explorar nuevas rutas de aproximación a problemas y posibles soluciones.

La serendipia implica también apertura a lo nuevo o inesperado. Muchas veces parece ser accidental una solución o bien una idea; por más incipiente que parezca, esta casualidad puede conducir a un territorio incógnito pero que se puede explorar y rendir procesos aún más ricos que la ruta original preestablecida, y al mismo tiempo abundar en terrenos donde aún no se ha generado alguna expectativa.

La serendipia como táctica de creatividad consiste en crear las condiciones necesarias para que ésta aflore, fluya, se desarrolle, madure y se vincule. Permite el descubrimiento de ideas, técnicas, texturas, conexiones nuevas. También da cabida al reencuentro con viejos conceptos para establecer nuevos vínculos, o bien, el desempolvar ideas olvidadas al retomar prácticas anteriores que recapitulan conceptos de manera más profunda. Así, esta táctica brinda la oportunidad para redimensionar el alcance del producto de la conceptualización de algo, también estar más conscientes de esas sutilezas y valores expresivos que han sido accidente o meras improntas.

Por ello, la serendipia puede cumplir con ciertas cualidades en su desarrollo -ya sea de forma separada o complementaria- y entre las que destacan el eclecticismo, el sincretismo y la crítica, propiciando en algún momento la síntesis.

La serendipia como táctica de una metodología enfocada a la creación plástica fomenta en el artista una postura que pone en crisis criterios anteriores y prejuiciados para abordar problemáticas novedosas desde posturas alternativas y propositivas, mismas que permitan la expansión del lenguaje artístico, pero sobretodo el desarrollo de actitudes proactivas por parte de los creadores, es decir, entrar en un cambio de modelo de procesar conocimientos y por ello la producción de la obra. La capacidad del visualización del artista debe siempre trascender los niveles de lógica y convencionalismos en todas sus vertientes (morales, religiosos, sociales, etc.) para lograr actos creativos genuinos y auténticos - el poder adaptar lo nuevo e inesperado de las circunstancias a la experiencia ya vivida y la práctica - para innovar, adaptar situaciones y lograr nuevas propuestas.

Es ecléctica porque está tomando influencias y códigos para fusionarlos con una búsqueda específica. En este sentido es heterodoxa y hasta irreverente al destruir dogmas. Mientras la ciencia pregunta ¿Por qué?, el arte proclama ¿Por qué no?. Es así que el arte tiende a ser irreverente, para causar impacto, crear su territorio y postura propias al apelar a experiencias estéticas particulares que propicien la reflexión y la audacia para comunicar otras posibilidades de percibir la realidad, ampliando los linderos, tanto del campo creativo como del perceptual (artista y espectador).

Por su parte, como consecuencia de la serendipia, el sincretismo puede resultar como una alternativa al proceso creativo y de construcción de la obra plástica a través de la conjunción de campos que coexisten y donde cada uno de ellos conserva su identidad y características propias, es decir, no 
necesariamente elimina sus preceptos, sino que concatena elementos, prácticas, conceptos y representaciones que brindan un producto novedoso.

La cualidad sintética de la serendipia implica un grado de pericia y magistralía en el manejo de conceptos y técnicas en perfecto equilibrio y fusión, que hacen del producto artístico algo único y trascendente a nivel individual o íntimo, así como para diversos públicos, tanto específicos, locales como diversos y generales. Fusiona los hallazgos en una nueva intención, ésta última más impactante que su antecedente, por parte del artista.

Aunque el origen de la palabra serendipia es un neologismo del idioma inglés acuñado por Horace Walpole en 1754, en la Real Academia Española este término no existe, existe chiripa, misma que se define como la suerte favorable que se gana por casualidad, o la casualidad favorable..$^{5} \mathrm{~A}$ la vez, chiripa es un mexicanismo incorporado oficialmente a la lengua española. ${ }^{6}$ Al respecto, la casualidad, el accidente y lo involuntario han permeado en el proceso creativo de connotados representantes del arte universal, entre los que destacan:

- $\quad$ Alexander Calder (creación del móvil),

- Henri Matisse (papel recortado como técnica pictórica),

- Johann Alois Senefelder (la invención de la litografía como sistema de impresión), Jackson Pollock (proceso de trance),

- Georges Mëliet (películas pintadas a mano, doble exposición y desvanecimiento),

- Martha Graham (técnicas de la danza contemporánea),

- $\quad$ Alvar Aalto (destacar el error en la construcción como elemento distintivo).

Hemos encontrado que existen varios tipos de serendipia:

En el primero buscas A y obtienes B. en la ciencia muchos de los grandes hallazgos, han sido por casualidad o chiripa. La serendipia operaba en el descubrimiento de Lucy, cuando el paleontólogo Donald Johanson ${ }^{7}$ buscaba otra evidencia de la antigüedad del Hombre, y se encontró con otro homínido, complican aun más la condición de nuestro origen. En las artes podemos poner el ejemplo de Marcel Duchamp en su obra "La novia puesta al desnudo por sus solteros”, incluso "Etant Donnés" (todo está dado) 1915-1923, que al ser trasladada al Museo de Filadelfia para su exposición sufre un accidente y se craquelan los vidrios. El museo estuvo muy apelado dado la importancia de la obra habiendo durando 8 años de construcción. Marcel Duchamp sin embargo encontró una validez y significado en que el vidrio se craquelara y hasta casi lo aplaudió, encontrando un valor en ello.

5 Diccionario de la Real Academia Española. lema.rae.es/drae/?val=/chiripa

6 Diccionario Breve de Mexicanismos, Guido Gómez de Silva, 2001:Academia Mexicana y FCE,: Mexico. p. 55.

7 Ver Donald Johanson. Lucy, The Beginnings of Humankind, 1981. Simon and Schuster, NY. 
En la segunda tipología de serendipia no buscas nada o no tiene nada planeado y encuentras algo. Te tropiezas con algo sin buscarlo. Como el caso de Amellia Fais Hamas, quien después de haber bebido mucho vino y manchado muchas prendas, retó a la ley de la gravedad par conseguir que ésta le ayudar a crear obras pictóricas y originales, donde el vino derramado modela pequeños rostros de tonos rosáceos a modo de apariciones de santos.

La tercera tipología de la serendipia empieza cuando se busca donde nunca se pensaba encontrar algo que se descubriría. En este rubro tenemos a Tim Noble and Sue Webster, quienes recrean en montañas creadas por bultos y envases de los basureros imágenes románticas e idílicas que con ayuda de iluminación proyectan otra imagen en siluetas de sombra.

En la cuarta tipología logra algo con lo que menos desea trabajar, es decir con lo que se detesta, se opone o se descarta. Esto crea obstáculos para el proceso fluido de asociaciones que uno hacer normalmente. Como ejemplo podemos aportar la estrategia pedagógica implantada en el departamento de arte de una universidad en Los Ángeles, California; donde se practicó una ruptura con los cánones y praxis del arte de ese tiempo. Al resolver un cuadro, ya sea de gráfica o pintura, el maestro demanda que el alumno trabaje o resuelva con los elementos que jamás se atrevería a utilizar. Es decir colores totalmente contradictorios o bien elementos pictóricos que no tendría la congruencia lógica. En esto se logra traspasar barreras al plantear retos inesperado para resolver.

3.

Como una tercera táctica metodológica se encuentran los multimedios, mismos que pueden ser definidos como el manejo de diversos elementos disciplinarios, técnicos y/o conceptuales para mostrar el acto expresivo del artista. Implican el cruzamiento de disciplinas para llevar a cabo de mejor forma la representación y transmisión de un mensaje determinado, múltiples maneras de investigar el tema de la obra, procesarla y plasmarla.

Aunque el término es tan antiguo como la comunicación humana pues involucra sonido -al comunicarse verbalmente-, texto -al hacerlo por escrito- y observación al mirar al interlocutor, los multimedios se constituyen como una alternativa incluyente a los modelos de pensamiento del practicante de las artes. Asimismo, promueve el desarrollo de una disciplina fundamentada en los estímulos mixtos y que trascienden el campo analógico para alcanzar los medios digitales. En tal sentido, texto, sonido, imagen, animación, video e interactividad confluyen para enriquecer el contenido expresivo y con ello, la experiencia estética por parte del espectador. Del mismo modo, esta práctica de interacción entre medios por parte del artista promueve el pensamiento complejo.

Al igual que otras tácticas, es necesaria la alimentación multisensorial para que, una vez abundados los estímulos en sus diversas gamas y alcances, el artista pueda elegir el o los canales ideales 
para la expresión de sus ideas de un proyecto dado, logrando así adaptar y sintetizar esta inventiva variable y permitiendo ampliar las fuentes de creación.

Como exponentes de este campo de desarrollo artístico podemos mencionar entre muchos otros a Mónica Mayer y Víctor Lerma, artistas mexicanos que afirman que (la multimedia) es:

\begin{abstract}
Una plataforma desde la que se organizan proyectos de arte conceptual aplicado, definiendo obras que además de cualquier valor simbólico pretenden intervenir de manera práctica su entorno proponiendo e implementando soluciones (...) lubricando el sistema artístico para que funcione mejor. ${ }^{8}$
\end{abstract}

Por otra parte, es digno de mencionar a Ernesto Neto, artista brasileño internacionalmente conocido por sus esculturas interactivas, que en realidad son mega instalaciones en las cuales el espectador "transita la obra" para habitarlas, sentirlas e incluso olerlas y con ello derivar en una experiencia multisensorial, además de su estética particular. Del mismo modo, utiliza múltiples materiales para enfatizar el impacto.

A través de la implantación de actividades teórico-prácticas, la pedagogía de las artes se nutrirá de aspectos conceptuales que nutran la idea que pueda resultar en un producto artístico de amplia envergadura y con un alto contenido de autenticidad y proyección en el lenguaje de la plástica contemporánea.

Mikhail Bakhtin establece en La imaginación dialógica, que:

\begin{abstract}
El diálogo y sus procesos diversos son centrales a la teoría de Bakhtin, y es precisamente en el proceso verbal que se percibe de manera más precisa, una palabra, discurso, idioma o cultura atraviesa por una "dialogización" cuando es relativizada, deprivilegiada, consciente de las relaciones en competencia para expresar lo mismo, el idioma no dialogizado es autoritario y absoluto. ${ }^{9}$
\end{abstract}

Así vemos a ésta como una ruta en que los diferentes senderos, materiales, técnicas y estrategias pueden tener perfecta cabida, permitiendo el diálogo constante y constructivo entre su autor y su novela así como entre el artista y los materiales, entre el artista y su bitácora, entre el artista y la serendipia o accidente, entre el artista y las disciplinas o medios, entre el artista y su obra, entre la obra y el espectador. Por lo tanto, existe un dialogismo entre las tácticas aquí delineadas: estableciendo la búsqueda de ideas y la interacción entre el creador y su creación. Todos estos aspectos involucran el manejo de múltiples posibilidades y el desarraigo de patrones establecidos a partir de la indagación en otros terrenos de la expresión artística y su relación con otras disciplinas del conocimiento.

8 "Una moneda de tres caras". Mónica Mayer y Víctor Lerma en www.pintomiraya.com/pmr/

9 Michael Holquist, Ed. “Glosario” en The Dialogic Imagination. 1981: University of Texas Press, pág. 427. 
El proceso que proponemos implica transgredir las fronteras ortodoxas de la academia y sus disciplinas formales. Mueve al investigador-artista fuera de la zona de confort previamente inculcada; sacude, pero le apoya en trascender hábitos; y le adiestra en el manejo de un lenguaje variado y rico. Después de todo, tanto el arte como cualquier investigación se valida con propuestas nuevas. 


\section{BIBLIOGRAFÍA}

Bakhtin Mikhail. The Dialogic Imagination, Four Essays. University of Texas Press. 1981. Diccionario de la Real Academia Española, 2014.

Foster Hal, "The Artist as Ethnographer" en The Return of the Real: The Avant-Garde at the End of the Century, 1996: MIT Press, Cambridge Massachusetts.

Gómez de Silva, Guido. Diccionario Breve de Mexicanismos, 2001: Academia Mexicana Fondo de Cultura Económica, Mexico

Holquist, Michael. Editor. Glosario en The Dialogic ilagination de Mikail Bakhtin. 1981: University of Texas Press, Austin.

Johanson, Donald. Lucy, The Beginnings of Humankind, 1981: Simon and Schuster, New York. Klee, Paul. Paul Klee's Notebooks, 1973: Wittenborn Art Books, Inc., New York.

\section{REFERENCIAS ELECTRÓNICAS}

- bitacoradeunartista.com

- “Una moneda de tres caras” Mónica Mayer y Víctor Lerma, www.pintomiraya.com/pmr/

- Ortega Rousset, Emiliano. http://permutaciones.wordpress.com/ 